\title{
A quem recorremos quando falamos sobre gênero na Comunicação? Aspectos de colonialidade e decolonialidade a partir da bibliografia utilizada nas pesquisas da área
}

\section{To whom do we call upon when we talk about gender and Communication? Aspects of coloniality and decoloniality from the bibliography used in research on the field}

\author{
Camilla Quesada Tavares ${ }^{1}$ \\ Michele Goulart Massuchin ${ }^{2}$ \\ Leila Lima de Sousa ${ }^{3}$
}

Resumo: O objetivo deste artigo é discutir, a partir das referências bibliográficas utilizadas em artigos que apresentam uma intersecção entre Comunicação e Gênero, como aspectos de colonialidade e decolonialidade aparecem na produção científica da área. Para isso, analisamos 155 artigos publicados nos periódicos Qualis A1 e A2, da área da Comunicação e Informação, entre 2000 e 2019, a partir da abordagem bibliométrica, com base em análise textual e de redes. Com essas estratégias, procuramos identificar as temáticas dos trabalhos e os autores mais utilizados nessas pesquisas. Nosso argumento é de que os fenômenos carecem de novas perspectivas epistemológicas, mas isso esbarra em diversos problemas, tais como o foco das referências advindas de países da Europa Ocidental e Estados Unidos.

1 Universidade Federal do Maranhão (UFMA). São Luís, MA, Brasil. https://orcid.org/0000-0001-5490-6850.E-mail: camilla.tavares8@gmail.com

2 Universidade Federal do Paraná (UFPR). Curitiba, PR, Brasil. https://orcid.org/0000-0001-7918-4487.E-mail: mimassuchin@gmail.com

3 Universidade Federal do Maranhão (UFMA). São Luís, MA, Brasil. https://orcid.org/0000-0003-2335-0858. E-mail: leilasousa.pi@gmail.com 
Palavras-chave: Comunicação e gênero; bibliografia; periódicos científicos; Sul Global; estudos decoloniais.

Abstract: The main purpose of this article is to discuss how aspects of coloniality and decoloniality appear in the scientific production of the area, based in the bibliographic references used in articles that present an intersection between Communication and Gender. To support this debate, we analyze 155 articles published in Qualis A1 and A2, in the area of Communication and Information, between 2000 and 2019, using the bibliometric method, combined with textual and network analysis. With these strategies, we seek to identify the themes of the works and the authors most used in this research. Our argument is that the phenomena lack new epistemological perspectives, but this comes up against several problems, such as the focus of references from Western European countries and the United States.

Keywords: Communication and gender; bibliography; scientific journals; Global South; decolonial studies. 


\section{Introdução}

A área da Comunicação e Gênero, no Brasil, vem crescendo desde a década de 1970 (SOARES, 1994), com o aumento do número de programas de pós-graduação e de trabalhos publicados em periódicos científicos nos últimos anos (TOMAZZETI, 2019; ESCOSTEGUY, 2019; MASSUCHIN; TAVARES; SILVA, 2020). Apesar de já se ter um indicativo tanto sobre as redes de autoria quanto dos principais objetos de estudo e métodos e técnicas mais utilizados nessas pesquisas, o campo ainda carece de investigações que se dediquem a observar, de modo sistematizado, onde esses fenômenos estão ancorados teórica e epistemologicamente. Assim, partimos do pressuposto de que a rede de referências mobilizadas pelos autores e autoras ajuda a compreender tendências, escolhas teóricas e metodológicas e o avanço do próprio campo. Portanto, este texto tem por objetivo mapear as temáticas e, principalmente, as bibliografias mais utilizadas nas pesquisas sobre Comunicação e Gênero publicadas no Brasil.

Na literatura tradicional sobre gênero - fortemente influenciada por pesquisadores e pesquisadoras de países da Europa Ocidental e Estados Unidos - há o reconhecimento de que as principais correntes de pensamento apresentam limitações para compreendermos o fenômeno de modo mais amplo e ancorado em realidades distintas. Isso porque muito da produção está baseado em uma realidade bastante diferente daquela enfrentada por mulheres pobres, negras, lésbicas, camponesas e residentes em países considerados periféricos, como os do Sul Global.

No Brasil, trabalhos desenvolvidos por Gonzalez (2011), Carneiro (2011) e Bairros (2014) colocavam em evidência a necessidade de deslocamento dos estudos de gênero para incorporar as intersecções entre gênero, raça, classe e sexualidade, na composição das hierarquias de poder e de desigualdades. Essa é uma assimetria identificada não apenas quando falamos em estudos de gênero, mas em todos os níveis da vida social, segundo defende a linha dos estudos decoloniais e pós-coloniais, que surge na América Latina a partir dos anos de 1990 (BALLESTRIN, 2013). Assim, defende-se o uso dessa lente analítica para compreender, 
também, os problemas e desigualdades de gênero presentes nessas sociedades (LUGONES, 2014; MENDES; FONSECA, 2020).

Mas será que as investigações brasileiras recorrem às perspectivas decoloniais para compreender os fenômenos que envolvem comunicação e gênero? Com o intuito de responder a essa pergunta, este trabalho analisou os temas e as referências utilizadas em 155 artigos publicados em periódicos nacionais com Qualis Al e A2, da área da Comunicação e Informação da Capes ${ }^{4}$, a partir do método bibliométrico, entre os anos de 2000 a 2019. Ao todo, 10 revistas dentro deste escopo publicaram artigos sobre a temática no período, a saber: Cadernos Pagu, Comunicação, Mídia e Consumo, Dados, E-Compós, Estudos Feministas, Famecos, Galáxia, Intercom, Matrizes e Opinião Pública.

Os artigos foram mapeados por integrantes do grupo de pesquisa Comunicação, Política e Sociedade (COPS), da Universidade Federal do Maranhão (UFMA), campus Imperatriz, e os conteúdos de indexação (título, autoria, universidades, resumo e palavras-chaves), bem como as referências bibliográficas empregadas em cada artigo, foram coletadas de forma manual e passadas para uma planilha do Excel. Após a coleta, uma pesquisa complementar foi realizada para incluir o país de origem e a universidade dos autores e autoras mais citados pelos trabalhos. Para este texto, utilizaremos dados referentes às palavras-chave e referências bibliográficas.

Já a análise dos dados foi realizada em duas etapas, a partir de dois softwares diferentes. A primeira consistiu na análise das palavras-chave, com o auxílio do software Iramuteq, que permitiu a criação do gráfico de similitude (SALVIATI, 2017), demonstrando quais as temáticas mais presentes nos trabalhos e ao que estão associadas. Já a segunda parte é resultado da extração das referências bibliográficas utilizadas nas pesquisas, a partir da análise de redes, viabilizada pelo software Gephi.

A análise bibliométrica (NARIN; OLIVASTRO; STEVENS, 1994; MACHADO JUNIOR et al., 2016; GUIMARÃES; BEZERRA, 2020)

4 O mapeamento foi realizado considerando o Qualis oficialmente vigente (2013-2016), em que ainda havia divisão por grandes áreas e os estratos "As" eram compostos apenas por duas categorias - $\mathrm{Al}$ e A2. 
nos permite compreender a produção de um país sobre determinado tema, a partir de um cenário micro ou macro (MACIAS-CHAPULA, 1998; OLIVEIRA, 2019). A partir desse mapeamento sistematizado, podemos ter um panorama sobre como os estudos de Comunicação e Gênero são enquadrados no Brasil, considerando o debate sobre colonialidade e decolonialidade das perspectivas teóricas e metodológicas. A agenda da descolonização e desocidentalização da pesquisa tem ganhado atenção há pelo menos duas décadas, mas seu impacto na produção internacional da área da Comunicação tem sido bem limitado (ALBUQUERQUE, 2020; ALBUQUERQUE et al., 2020), como veremos a seguir.

O texto segue dividido da seguinte forma: no próximo tópico apresentamos os resultados empíricos do mapeamento bibliográfico, indicando os padrões analíticos e as lacunas de investigação verificadas por meio das principais referências, redes de citação e temáticas. Na sequência, discorremos sobre os estudos decoloniais que poderiam ser mais bem mobilizados pelas pesquisas brasileiras considerando a subárea da Comunicação e Gênero. Por fim, apresentam-se as conclusões, onde discutimos sobre as dificuldades que atravessam a visibilidade das publicações do Sul Global, especialmente no que tange à sua inserção no rol de periódicos internacionais de relevância, por serem provenientes de países considerados periféricos e de "Terceiro Mundo", efeitos do que os estudos identificam como "colonialidade do saber".

\section{A ótica dos estudos de gênero na Comunicação a partir da análise bibliográfica}

Para compreender as referências mobilizadas nos trabalhos que integram este artigo, acreditamos ser interessante conhecer do que tratam essas pesquisas. Para isso, apresentamos a seguir a análise de similitude, a partir de um grafo gerado, considerando as palavras-chaves das 155 publicações. Este tipo de análise permite inferir "a estrutura de construção do texto e os temas de relativa importância, a partir da coocorrência 
entre as palavras" (SALVIATI, 2017, p. 69). A partir dela, percebemos que a categoria de gênero que predomina nas análises é a mulher, abordada pelo recorte teórico do feminismo, porém boa parte dos trabalhos não discute aspectos interseccionais ou pelo viés da consubstancialidade (HIRATA, 2010). Em nosso corpus, apenas 11 artigos apresentam discussões interseccionais. E, notadamente, apesar da ampliação dos estudos que contemplam outras categorias de gênero e do surgimento de novas abordagens nos estudos da área nas últimas décadas como o foco em sexualidade e masculinidades (GROSSI, 2004), elas ainda não têm proeminência comparando-se com a categoria mulher (e suas derivações, como feminino, feminismo, feminina, feminilidade etc.).

Figura 1 - Grafo de similitude das palavras-chaves dos artigos publicados.

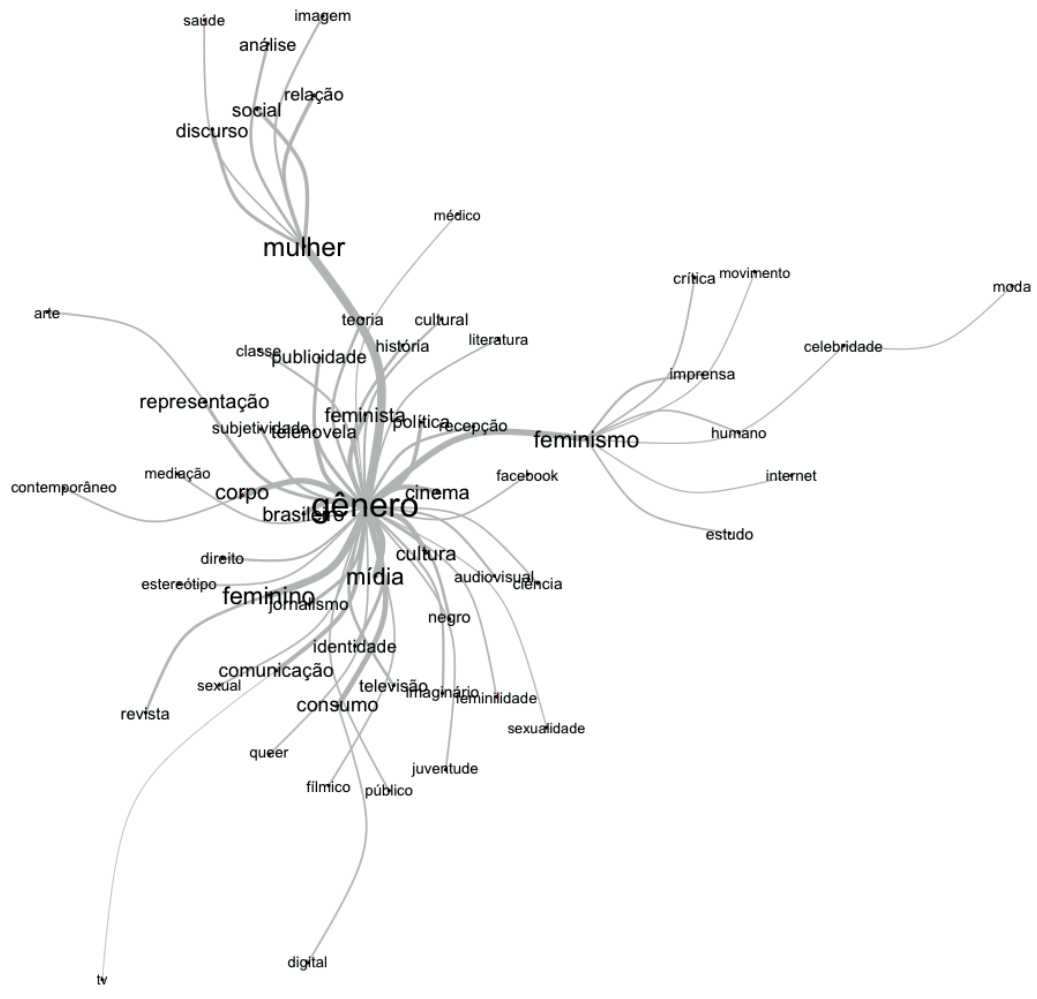

Fonte: Arquivo das autoras (2020) 
Já o tipo de estudo diz respeito, majoritariamente, às representações construídas pelo discurso midiático, o que é um recorte metodológico bastante frequente na Comunicação, tanto em uma perspectiva nacional (ESCOSTEGUY, 2019, 2008; SARMENTO, 2013) quanto internacional (DOW; CONDIT, 2005). Por se tratar de revistas brasileiras, além disso, a maioria dos artigos está escrita em língua portuguesa e refere-se ao contexto brasileiro, por isso o destaque à palavra. Se por um lado isso representa uma crescente dos estudos de Comunicação e Gênero sobre o cenário do Brasil, por outro indica a centralidade em casos específicos e a baixa presença de pesquisas comparativas, o que não é uma característica apenas deste campo, sendo um desafio para as pesquisas em Comunicação de forma geral (WIRTH; KOLB, 2004).

Também se destacam os termos cinema e fílmico, que aparecem como subárea e objeto, respectivamente, de forma bastante relevante. Neste sentido, os estudos sobre o audiovisual têm oferecido considerações bastante centrais nas pesquisas sobre gênero perpassando por diversas questões, como interseccionalidade, representação e a crítica aos corpos sexualizados (VEIGA, 2017), da mesma forma que as análises a partir da perspectiva política, com estudos sobre cobertura e representação de mulheres políticas (MIGUEL; BIROLI, 2014), o que vai ficar mais claro com a observação das referências utilizadas.

Em relação às referências que foram catalogadas nos 155 artigos, ao todo foram 3.464 citações, o que gera uma média de 22 referências por trabalho. A partir desses dados, consideramos neste artigo que as referências podem dar indícios relevantes sobre como aspectos de colonialidade e decolonialidade aparecem na produção científica da área. Do mesmo modo, mostram traços e caminhos pelos quais as pesquisas publicadas se deslocam, a partir das escolhas feitas sobre a literatura utilizada como base teórica, epistemológica e metodológica. Como os autores e autoras referenciados podem ser os mesmos ou até mesmo a partir de obras distintas, foram totalizadas 2.007 autorias únicas. Assim, a rede de autoria está relacionada a todos os autores citados, sendo catalogados aqui uma única vez; enquanto a rede de citações refere-se a todas as vezes em que 
os(as) autores(as) foram citados(as), incluindo diferentes obras de mesma autoria. A primeira relaciona-se ao número de autores, enquanto a segunda à quantidade de vezes que esse autor apareceu nas referências. A Tabela 1 sistematiza o resultado considerando o total de autorias e de citações.

Tabela 1: Dados gerais sobre autores(as) e citações

\begin{tabular}{c|c|c}
\hline Quantidade de citações & Quantidade de autores/as & Total de citações \\
\hline 1 & 1.512 & 1.512 \\
2 & 266 & 532 \\
Entre 3 e 9 & 198 & 862 \\
10 ou mais & 31 & 558 \\
\hline Total & $\mathbf{2 . 0 0 7}$ & $\mathbf{3 . 4 6 4}$ \\
\hline
\end{tabular}

Fonte: Arquivo das autoras (2020)

A partir dos resultados, constatamos que não há, de fato, elevada centralização em determinados autores da área, ainda que alguns casos se destaquem como veremos na sequência. No geral, há uma pulverização bastante evidente das referências, ainda que aqui sejam consideradas tanto aquelas inerentes aos estudos de gênero quanto as que tratam dos demais assuntos. Porém, como todos os trabalhos, ainda que dentro de suas subáreas da Comunicação, dialogam com uma questão central que são os estudos de gênero -, é esperado que esses autores e autoras tenham maior proeminência porque seriam aqueles que poderiam circular por todos os textos. Dos 2.007 autores e autoras que receberam ao menos uma referência, somente 31 tiveram 10 ou mais citações. Considerando que podem ser citadas mais de uma obra do(a) mesmo(a) autor(a) em cada artigo - como é o caso de Pierre Bourdieu, por exemplo, que aparece 46 vezes, mas somente em 26 artigos -, evidencia-se ainda mais essa pulverização. Embora os estudos sobre Comunicação e Gênero sejam vistos como uma intersecção consolidada, com abordagens internas já passíveis de serem definidas (ESCOSTEGUY, 2019; 2008; DOW; CONDIT, 2005; MENDES; CARTER, 2008), parece não ocorrer o mesmo com as bases das pesquisas. 
Essa pulverização - apesar de demonstrar uma ampliação crescente da área - também pode indicar certa dificuldade de amparo teórico, seja mobilizando mais autores(as) dos estudos de gênero para fortalecer a intersecção ou evidenciando aqueles(as) que, dentro desta subárea, já construíram suas trajetórias e propuseram teorias e abordagens para os estudos em Comunicação e Gênero. Essa hipótese ancora-se no fato de que 1.512 autores foram citados uma única vez nos trabalhos, o que representa $43,6 \%$ do total de citações.

A partir desses dados iniciais, busca-se agora entender alguns pontos-chave sobre o eixo colonialidade e decolonialidade. Para isso, o Quadro 1 mostra quem são os(as) autores(as) que mais foram referenciados(as), lembrando que pode não se tratar necessariamente da mesma obra, ainda que em muitos casos tenha-se observado a permanência das citações de determinados livros ou artigos. É o caso, por exemplo, de Michel Foucault, que aparece, majoritariamente, em função da obra História da Sexualidade. Isso se repete no caso de Joan Scott, com o texto Gênero: uma categoria útil para análise histórica e Judith Butler, com Problemas de Gênero.

De modo geral, cerca de metade dos autores e autoras (16) que mais aparecem como referência possuem algum tipo de produção - ainda que em diferentes momentos da trajetória acadêmica - sobre estudos de gênero. Boa parte são de reflexões de áreas correlatas - filosofia, ciência política etc. - que trazem a perspectiva de gênero para a discussão. Outras referências, no entanto, já são consolidadas em subáreas da Comunicação, como é o caso da área de Cinema com Laura Mulvey e Teresa de Lauretis, o que já havia sido identificado por Veiga (2017).

Chamam a atenção também as citações a Michel Foucault (60 feitas em 33 artigos, já que são várias obras referenciadas) e Pierre Bourdieu (46 em 26 artigos, também com mais de uma obra por artigo, em média) no topo do ranqueamento das referências, e suas obras referenciadas são mais pontuais sobre o tema em comparação com outros(as) autores(as) que possuem uma trajetória mais centrada e longa dentro dos estudos de gênero, como é o caso de Judith Butler, Ana Carolina Escosteguy e 
Joan Scott. Butler, por exemplo, tem uma vasta produção recente em comparação com os referidos autores.

Quadro l - Distribuição das citações dos autores mais referenciados.

\begin{tabular}{|c|c|c|c|}
\hline Autores citados & Freq. da citação & Origem & Instituição \\
\hline *FOUCAULT, Michel. & 60 & França & Collège du France \\
\hline *BOURDIEU, Pierre. & 46 & França & Collège du France \\
\hline *BUTLER, Judith. & 31 & Estados Unidos & Universidade da Califórnia \\
\hline HALL, Stuart. & 30 & Jamaica & Universidade de Birmingham \\
\hline MARTIN-BARBERO, Jesús. & 27 & Espanha & Universidade Valle de Calli \\
\hline *ESCOSTEGUY, Ana Carolina. & 25 & Brasil & PUC-RS \\
\hline *SCOTT, Joan. & 23 & Estados Unidos & Estudos Avançados de Princeton \\
\hline LÉVINAS, Emmanuel. & 23 & França & Universidade de Paris \\
\hline *MIGUEL, Luis Felipe. & 18 & Brasil & UnB \\
\hline FREIRE FILHO, João. & 17 & Brasil & UFRJ \\
\hline GIDDENS, Anthony. & 16 & Inglaterra & Escola de Economia de Londres \\
\hline BARTHES, Roland. & 16 & Normandia & CNRS \\
\hline BAUDRILLARD, Jean. & 16 & França & Sorbonne \\
\hline ROCHA, Everardo. & 14 & Brasil & PUC-Rio \\
\hline *PERROT, Michelle. & 14 & França & Universidade de Paris VII \\
\hline *DE LAURETIS, Teresa. & 14 & Itália & Universidade da Califórnia \\
\hline * MULVEY, Laura. & 13 & Inglaterra & Universidade de Londres \\
\hline LIPOVETSKY, Gilles. & 13 & França & Universidade de Grenoble \\
\hline FISCHER, Rosa Maria Bueno. & 13 & Brasil & UFRGS \\
\hline *RONSINI, Veneza Mayora. & 12 & Brasil & UFSM \\
\hline MAFFESOLI, Michel. & 12 & França & Universidade de Paris \\
\hline *McROBBIE, Angela. & 12 & Inglaterra & Universidade de Londres \\
\hline *MODLESKI, Tania. & 11 & Estados Unidos & Universidade da Califórnia \\
\hline HABERMAS, Jürgen. & 11 & Alemanha & Universidade Heidelberg \\
\hline COSTA, Jurandir Freire. & 11 & Brasil & UFRJ \\
\hline MORLEY, David. & 10 & Inglaterra & Universidade de Goldsmiths \\
\hline *PRECIADO, Paul Beatriz. & 10 & Espanhol & Universidade de Paris III \\
\hline *HAMBURGUER, Esther. & 10 & Brasil & USP \\
\hline CANCLINI, Nestor Garcia. & 10 & Argentina & Universidade Autônoma do México \\
\hline${ }^{*} \mathrm{ANG}, \mathrm{Ien}$ & 10 & Indonésia & Universidade de Sidney \\
\hline *ALMEIDA, Heloisa Buarque de. & 10 & Brasil & USP \\
\hline
\end{tabular}


Outra questão que chama a atenção na pesquisa é que parte significativa das obras referenciadas refere-se àquelas traduzidas para o português, tornando-se mais acessíveis. A partir disso, é importante reforçar que os exercícios de tradução - no caso desses autores centrais - dizem muito da posição que ocupam. Costa (2003) reforça, por exemplo, o papel das revistas feministas - e pode-se incluir aqui editoras - que fazem traduções contribuindo com a circulação transnacional de teorias ou conceitos. Porém, se por um lado este processo é positivo para que haja circulação para além das fronteiras de um campo interdisciplinar entre Norte e Sul (COSTA, 2003), argumenta-se que isso pode gerar - de outro modo - um norteamento das abordagens e quase não há um percurso oposto (do Sul ao Norte). Vale destacar que a política de citações acaba direcionando para este insight, reforçando o que Costa (2003) chama de "rede de influências transnacionais".

E, se por um lado os estudos de Comunicação e Gênero já contam com uma trajetória de pelo menos 20 anos de publicações de maneira mais evidente no Brasil, sendo possível construir até mesmo uma metapesquisa (ESCOSTEGUY, 2019), isso não significa - necessariamente - que essa subárea constrói discussões próprias a partir da apropriação da literatura estrangeira, que é majoritária entre os referenciados com mais frequência. De 16 autores e autoras sobre gênero que estão no topo do ranqueamento, apenas cinco são brasileiros(as), porém tendem a ser referenciados(as) nas suas respectivas subáreas de forma mais estrita: Ana Carolina Escosteguy, Veneza Ronsini, Esther Hamburguer, Heloisa Almeida e Luis Felipe Miguel ${ }^{5}$.

Outra informação central para a qual esses dados lançam luz, aproximando-se mais do aspecto decolonial a ser debatido, é que os estudos de autores latino-americanos - ou mesmo do Sul Global, olhando para outras regiões, como a Ásia ou África -, apesar de aparecerem entre as referências, não estão diretamente relacionados à discussão de gênero. É o caso de Stuart Hall, que é jamaicano, embora sempre tenha atuado na

5 Neste último caso, parte das referências não são necessariamente sobre as discussões de Gênero que o autor faz de maneira direta ao longo dos últimos 10 anos. 
Inglaterra; Néstor Canclini, que é argentino e atua no México; e Jesús Martín-Barbero, espanhol de nascença, mas radicado na Colômbia. Todos eles apresentam algum aspecto de decolonialidade - seja no seu país de origem ou naquele em que atua, mas não podem ser considerados totalmente de fora do eixo, além de não pertencerem, originalmente, à subárea em questão. Dentre os(as) autores(as) mais citados(as), a única exceção entre pesquisadores(as) internacionais é Ien Ang, que é da linha de estudos de gênero, nascida na Indonésia e pesquisadora da Universidade de Sidney, na Austrália.

Os dados também mostram, por outro lado, a entrada de novas perspectivas e abordagens de gênero, como é o caso dos estudos sobre sexualidade, trazidos por Paul Beatriz Preciado. No entanto, é preciso salientar que se trata de um autor espanhol e com atuação na França, com obras também traduzidas para o português, como o Manifesto Contrassexual. No caso de Judith Butler, embora a autora seja representativa dos estudos queer e da discussão sobre outras categorias de gênero, acaba sendo referenciada e trazida para a discussão quase que majoritariamente em trabalhos sobre mulheres. Para demonstrar a centralidade dos autores que dialogam com os estudos de gênero mais citados nos trabalhos, apresentamos a rede na Figura 2. Ela foi construída considerando 16 autores(as) da subárea de gênero que possuem pelo menos 10 citações. 
Figura 2 - Rede dos(as) autores(as) de gênero mais citados(as) nos artigos.

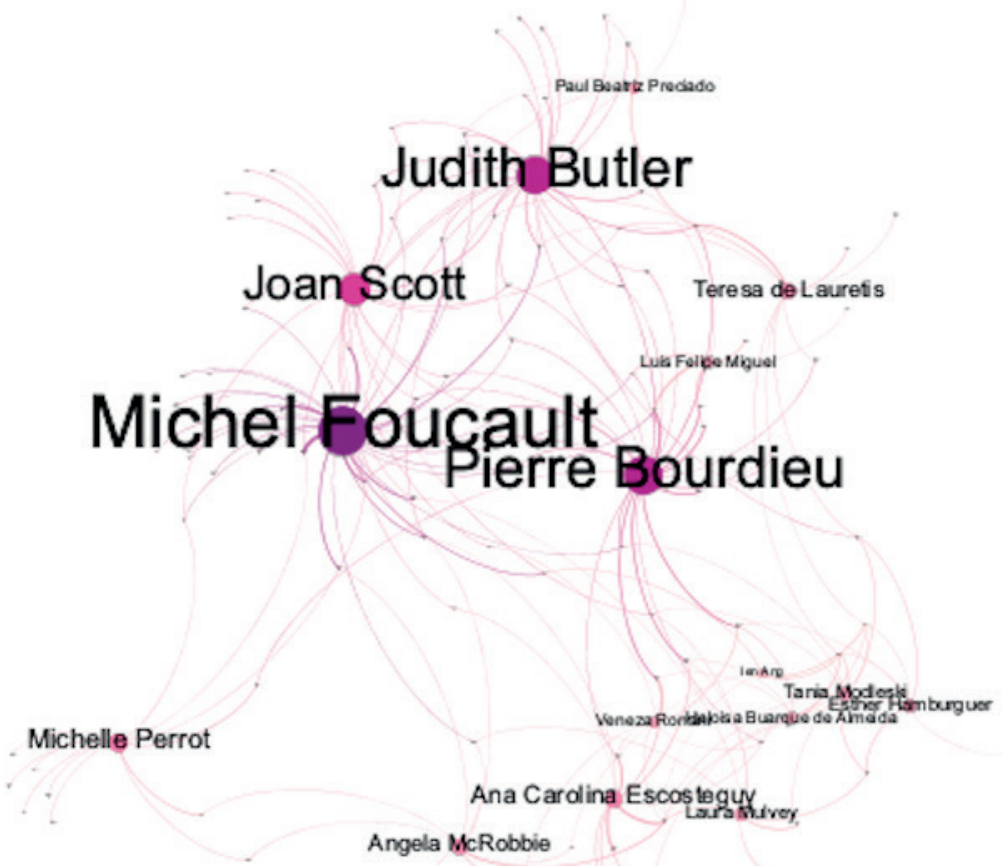

Fonte: Arquivo das autoras (2020)

O grafo foi construído a partir do algoritmo ForceAtlas, que representa espacialmente as ligações entre nós. A estatística utilizada foi o grau de entrada, ou seja, a quantidade de ligação - ou, neste caso, citação - que cada nó recebeu. Como já identificado no Quadro 1, Foucault e Bourdieu foram os autores mais citados, e são os mais centrais no grafo, indicando que estabelecem fortes ligações entre si e com outros autores da lista de referências. Judith Butler, apesar de aparecer em terceiro lugar na lista dos mais citados, apresenta o maior grau de centralidade (betweeness) da rede. Isso significa que é um hub que conecta diferentes referências e perspectivas teóricas - o ponto em comum em diferentes trabalhos. Ela é a única referência de gênero que dialoga diretamente com Paulo Preciado, por exemplo, que se dedica aos estudos sobre 
sexualidade, como dito anteriormente. Ao mesmo tempo, está presente em vários trabalhos que referenciam também Michel Foucault.

Bourdieu, por outro lado, é o autor que mais dialoga com as autoras brasileiras nos trabalhos analisados, já que é o nó principal que se liga a Ana Carolina Escosteguy, Heloisa Buarque de Almeida, Esther Hamburguer e, também, Luis Felipe Miguel, que trabalha com a intersecção entre os campos político e midiático. No geral, os(as) autores(as) que aparecem criando as redes e se posicionam como mais centrais nela não são brasileiros e, tampouco, de outros países do Sul Global.

Os dados revelam ainda que as investigações sobre gênero se centram majoritariamente na discussão sobre o feminismo, a partir de uma perspectiva heteronormativa. Dos 155 artigos que compõem o corpus desta pesquisa, 121 referem-se à mulher como categoria analítica. Estudos sobre masculinidades, gays, lésbicas, travestis, transexuais, transgênero, drag queens, sexualidade e bissexualidade são pouco contemplados no nosso recorte, já que todas essas categorias, juntas, estiveram presentes em apenas 34 artigos publicados nas revistas Al e A2 da área da Comunicação e Informação, entre 2000 e 2019, no Brasil. A ampliação da categoria gênero como uma construção histórica e social e que abarca outros elementos analíticos ainda aparece pouco problematizada e centrada em autores com bases epistêmicas euro-americanas.

Estudos sobre gays, lésbicas e transgêneros - os chamados gêneros não normativos (COLLING et al., 2012) - são realizados no Brasil desde a década de 1990. Na área da Comunicação, investigações desenvolvidas por Denilson Lopes (2001; 2004), por exemplo, tensionam ressignificações estéticas importantes realizadas no audiovisual por autores e produtores gays, como é o caso do melodrama. São estudos que há décadas vêm propondo uma leitura entre as categorias comunicação, gênero e sexualidade para além da heteronormatividade. Nesse sentido, a categoria "travesti" emerge como horizonte analítico e proposta epistemológica na tentativa de borrar as fronteiras impostas à sexualidade, ao propor necessárias fissuras entre os binarismos masculino e feminino, heterossexual e homossexual (LOPES, 2004), apesar de ainda haver 
poucos estudos dessa natureza publicados nas revistas investigadas neste artigo.

Por fim, a partir de outra demonstração sobre aspectos do processo de colonização da discussão sobre gênero, é preciso reforçar a invisibilidade dos diversos debates já consolidados nos estudos decoloniais como aqueles feitos por Lugones (2020), Curiel (2014; 2020), Miñoso (2014), Gonzalez (2011), Carneiro (2011) e Bairros (2014). Se pensarmos a partir da ideia de que as referências dão pistas sobre as abordagens teóricas e metodológicas, a partir das "redes transnacionais" (COSTA, 2003), podemos dizer que essa rede é quase inexistente do ponto de vista do Sul, quando se fala em Comunicação e Gênero. As autoras que se denominam como decoloniais a partir da perspectiva de gênero aparecem de forma insignificante se comparada às demais já citadas e que aparecem de forma sistemática nos trabalhos. As poucas citadas são Sueli Carneiro, com quatro referências, e Lélia Gonzalez, com uma única referência. Nestes dois casos, ambas são brasileiras e se esperaria, ao menos, um diálogo entre elas quando das referências aos estudos interseccionais, seja no eixo de raça ou classe, por exemplo, que cresceram na última década.

Esses dados apresentados, portanto, mostram um recorte que sinaliza um retrato sobre a colonialidade nos estudos sobre gênero publicados nas revistas qualificadas em Comunicação, com um debate muito centrado nos Estados Unidos e Europa quando se trata das principais e de parte significativa de toda a literatura citada, considerando os mais de dois mil autores e autoras. Isso, possivelmente, também está relacionado à outra discussão, que faremos a seguir, que é sobre a centralidade das autoras e autores em universidades e grandes centros das duas regiões citadas e da ausência de autores do Sul Global ocupando espaços de referência em publicações em inglês que, depois das traduções, acabam sendo a ponte para outros estudos e pesquisas. 


\section{As teorias (não) mobilizadas e a invisibilidade dos estudos do Sul Global}

O processo de análise das referências e teorias mobilizadas para problematizar as intersecções entre Gênero e Comunicação permitiu identificar que o conceito "gênero" é mobilizado como categoria nos trabalhos analisados, ainda que não tenhamos medido a intensidade do debate sobre este aspecto. Porém, autores do eixo euro-americano compõem majoritariamente os referentes teórico-metodológicos que sustentam as investigações brasileiras. Embora alguns autores citados apresentem relevante contribuição para os estudos de gênero, o não acionamento de perspectivas teóricas advindas, principalmente, de contextos latino-americanos e africanos, em que a categoria mulher e a categoria gênero são ampliadas, confrontadas e problematizadas desde outras bases, pode indicar que os estudos em Gênero e Comunicação no Brasil carregam muitos aspectos da "colonialidade do saber" (CURIEL, 2020).

O gênero, ao que parece, pode estar sendo utilizado como categoria analítica acionada para explicar a situação mundial de subordinação das mulheres, sem levar em consideração que, em sociedades colonizadas, o sistema de gênero foi imposto como tecnologia para conferir humanidade ou não aos sujeitos (LUGONES, 2014). Além disso, há que se questionar se o modelo de gênero se constitui como um sistema de divisão válida em outras sociedades para além do imposto pela colonialidade da Europa ocidental (OYĚWÙMÍ , 2004; BAKARE-YUSUF, 2003).

Oyěwùmí (2004) e Bakare-Yusuf (2003), intelectuais africanas, denunciam que boa parte das pesquisas sobre gênero são desenvolvidas a partir da experiência euro-americana. Oyěwùmí (2004) critica os estudos feministas que partem da discussão sobre o gênero como categoria usada para explicar a subalternização das mulheres porque o conceito, além de não ser universal, é também compreendido por tais estudos dentro da construção "nuclear" da família, modelo de organização familiar que não representa diversas outras sociedades. O gênero atua, nessa divisão, como principal modelo de organização da família e das divisões 
dos papéis. Dentro dessa lógica, raça e classe não são tomadas como critérios analíticos em muitas pesquisas brasileiras, ainda que estes eixos certamente atravessem essa realidade.

$\mathrm{E}$, diferentemente do modelo analítico pensado pelo feminismo branco, por exemplo, que coloca em evidência o gênero como critério principal da diferença, as intelectuais africanas problematizam o modelo familiar. Além de sociedades africanas, também as comunidades indígenas pré-coloniais não se baseavam no gênero como sistema de divisão familiar e social (CURIEL, 2020; LUGONES, 2020). A compreensão de que o sistema de gênero foi imposto em sociedades colonizadas como categoria binária de hierarquização e de diferenciação racial permite observar que aos sujeitos colonizados era negada a humanidade e, por sua vez, o gênero. Essas questões, no entanto, não são problematizadas ou consideradas nas pesquisas analisadas, inclusive porque a interseccionalidade ainda não é tema central nas pesquisas. Embora haja alguns esforços neste sentido na última década, ainda são poucos mediante o total de publicações.

Trazendo essa discussão para o cenário das referências, o feminismo decolonial, ao compreender o gênero como uma construção da colonialidade, identifica que ele está intimamente relacionado à hierarquização do saber (MIÑOSO, 2014). Ao problematizar tal perspectiva, Miñoso (2014) esclarece de que maneira o poder colonial atua em diferentes grupos subalternos, observando que a opressão também é desenvolvida através da dominação pelo conhecimento - o "saber-poder" que legitima e hierarquiza determinadas vozes (MIÑOSO, 2014, p. 8). Neste caso, embora muitas autorias sejam de mulheres, reforçamos a presença dos dois principais autores no ranking da citação e que, por não haver espaço para saberes do Sul e uma dependência do eixo europeu, principalmente, há um processo de hierarquização que desconsidera contextos importantes.

Curiel (2020) identifica o desengajamento epistemológico como estratégia para contrapor os impactos da colonialidade nos processos de subalternização das mulheres do Terceiro Mundo. Para ela, a 
colonialidade do saber fundamenta privilégios epistêmicos e cria a narrativa de que os conhecimentos produzidos nos eixos Europa e Estados Unidos são os únicos conhecimentos válidos. E isso fica bastante claro quando observamos as referências de gênero utilizadas nos principais artigos da área, analisados neste trabalho.

Apesar de haver autoras brasileiras que partem de uma discussão latino-americana, como Ana Carolina Escosteguy, a perspectiva teórica que predomina é a euro-americana, com autoras e autores que trabalham com conceitos considerados normativos ou que pouco são tensionados com abordagens do Sul Global. Judith Butler é o exemplo mais preponderante. A autora discute o conceito de gênero e é mobilizada em diferentes trabalhos, mas aparentemente a discussão serve apenas como pano de fundo teórico-metodológico, já que não se identifica um avanço no entendimento do próprio conceito. Outro ponto que merece destaque é a falta de autores e autoras da perspectiva decolonial ou pós-colonial, reforçados neste tópico para mostrar que há outras abordagens, porém pouco mobilizadas na produção analisada, como os dados já indicaram. Os limites e consequências da bibliografia normativa empregada nos estudos brasileiros de gênero são debatidas a seguir.

\section{Conclusão}

A crítica à perspectiva ocidental da produção intelectual não é recente, tampouco concentrada em apenas uma área do conhecimento, mas ainda é incipiente a quantidade de publicações de pesquisas e perspectivas provenientes de países do Sul Global nas revistas internacionais consideradas de prestígio (ANG et al., 2019). O principal motivo encontrado para explicar essa assimetria é o legado colonial deixado pelos países europeus, mas Albuquerque et al. (2020) oferecem uma via alternativa e complementar de interpretação, relacionada ao processo de globalização neoliberal que promove uma homogeneização da agenda de pesquisa em torno dos Estados Unidos. No caso da América Latina, os autores argumentam que seu status foi rebaixado quando o sistema 
de classificação centrado nos Estados Unidos foi estabelecido (ALBUQUERQUE et al., 2020).

Se por um lado há uma dificuldade em publicar em revistas internacionais, predominantemente de língua inglesa e com conselhos editoriais dominados por pesquisadores de poucos países, como Estados Unidos, Canadá e Inglaterra (ALBUQUERQUE et al., 2020), por outro observa-se a construção de uma rede em torno das instituições educacionais ocidentais, que recebem pesquisadores de todas as partes do mundo. A inserção nas universidades consideradas "de ponta" contribui, em certa medida, para o reforço da adoção de determinadas teorias que são, muitas vezes, estranhas às suas origens culturais e que dificilmente ajudam a compreender a realidade de suas sociedades. Assim, a centralidade no Ocidente também é promovida por pesquisadores não ocidentais (ALBUQUERQUE, 2020), seja quando migram para tais centros, seja quando reproduzem determinadas referências. Descolonizar o pensamento é um processo de ruptura com vínculos ocidentais propondo uma contraposição epistêmica (MIGNOLO, 2008).

A manutenção da centralidade das universidades e instituições ocidentais resulta no que Curiel (2020) chama de colonialidade do saber, e alguns aspectos disso foram identificados na produção intelectual sobre Gênero e Comunicação no Brasil a partir deste trabalho. A pouca ou nenhuma menção, nas pesquisas analisadas, a autoras negras e indígenas, latino-americanas, caribenhas e/ou africanas pode sinalizar que alguns conceitos e teorias ainda são reproduzidos sem que a realidade de outros contextos seja problematizada e que o saber/conhecimento seja situado a partir da experiência de mulheres que sofrem os impactos da noção de gênero em outra perspectiva. Majoritariamente, as autoras que propõem esta discussão não estão nas universidades mais centrais, as publicações não ganham visibilidade em publicações internacionais e algumas ainda não possuem tradução, o que torna o processo de incorporação ainda mais complexo.

Dado esse contexto, a produção intelectual mobilizada para discutir gênero ainda aciona, em sua maioria, estudos produzidos no eixo 
euro-americano, em detrimento da produção intelectual de referência desenvolvida no Sul Global. A hierarquização de saberes e a legitimação do eixo Europa-Estados Unidos como detentores de modelos válidos e únicos de construção do conhecimento resultou em um processo de sistemático apagamento, silenciamento e subalternização de saberes e conhecimentos ancestrais, frutos de culturas que foram subjugadas pelas culturas dominantes e hegemônicas.

No Brasil, a busca de fugir de uma "guetização epistemológica" fez com que os estudos sobre gays, lésbicas e transgêneros buscassem aproximações aos estudos culturais numa estratégia de visibilidade (LOPES, 2001, p. 6). As análises realizadas indicam a necessidade de ultrapassar fronteiras que fabricam dicotomias binárias centradas nas categorias homem-mulher, heterossexual-homossexual, ainda que estejam refletindo sobre processos decoloniais na construção do conhecimento. Esses trabalhos analisados parecem não se apoiar em autores que têm confrontado a norma heterossexual como ponto de partida para a compreensão da sexualidade, tampouco se utilizam de pesquisadores brasileiros para fazer esse tipo de discussão, apesar de haver estudiosos nacionais se dedicando a essas questões (COLLING et al., 2012).

No recorte analisado, os autores mais referenciados são homens e brancos. Pela identificação das palavras-chaves que compõem as produções, podemos inferir que ainda prevalece um sentido branco, proposto como universal, sobre a categoria mulher - principal eixo de abordagem nos estudos sobre Comunicação e Gênero no Brasil. Lélia Gonzalez, Sueli Carneiro e Luiza Bairros são autoras brasileiras que muito contribuíram para problematizar a suposta universalidade da categoria mulher, propondo intersecções analíticas de raça, classe e etnia. Mas, ainda assim, suas produções foram muito pouco recuperadas, no recorte analisado, para dar conta da dimensão e das particularidades do contexto Sul Global, já que estudos interseccionais ainda são pouco presentes na área de Comunicação e Gênero.

A luta contra os impactos do colonialismo, segundo acredita Escobar (2011), que também perpassa a produção acadêmica do próprio Sul, 
atravessa a ação dos povos subalternizados na recuperação dos elementos de referência que os constituem como e enquanto sujeitos históricos autônomos, políticos, econômicos e culturais. Para isso é preciso mobilizar teorias até então não mobilizadas, na tentativa de provocar rupturas na hegemonia intelectual acadêmica.

\section{Referências}

ALBUQUERQUE, A. The institutional basis of anglophone western centrality. Media, Culture \& Society, no prelo, p. 1-19, 2020.

ALBUQUERQUE, A. et al. Structural Limits to the De-Westernization of the Communication Field: The Editorial Board in Clarivate's JCR System. Communication, Culture and Critique, v. 13, n. 2, p. 185-203, 2020.

ANG, P. H. et al. Intellectual balkanization or globalization: the future of communication research publishing. Journalism \& Mass Communication Quarterly, v. 96, n. 4, p. 963-979, 2019.

BALLESTRIN, L. América Latina e o giro decolonial. Revista Brasileira de Ciência Política, n. 11, p. 89-117, 2013.

BAIRROS, L. Nossos feminismos revisitados. In: MIÑOSO, Y. E.; CORREAL, D. G.; MUÑZZ, K. O. Tejiendo de otro modo: Feminismo, epistemología y apuestas descoloniales en Abya Yala. Popayán: Editorial Universidad del Cauca, 2014. p. 181-188.

BAKARE-YUSUF, B. Além do determinismo: A fenomenologia da existência feminina Africana. Feminist Africa, n. 2, 2003.

CARNEIRO, S. Racismo, sexismo e desigualdade no Brasil. São Paulo: Selo Negro, 2011.

CHAKRAVARTTY, P. et al. \#CommunicationSoWhite. Journal of Communication, 2018. DOI:10.1093/joc/jqy003.

COLLING, L. et al. Um panorama dos estudos sobre mídia, sexualidades e gêneros não normativos no Brasil. Gênero, Niterói, v. 12, n. 2, p. 77-108, 2012.

COSTA, C. L. As publicações feministas e a política transnacional da tradução: reflexões do campo. Revista Estudos Feministas, Florianópolis, v. 11, n. 1, p. 254-264, 2003. CURIEL, O. Hacia la construcción de un feminismo descolonizado. In: MIÑOSO, Y. E.; CORREAL, D. G.; MUÑOZ, K. O. Tejiendo de otro modo: Feminismo, epistemología y apuestas descoloniales en Abya Yala. Popayán: Editorial Universidad del Cauca, 2014. p. 325-334.

CURIEL, O. Construindo metodologias feministas a partir do feminismo decolonial. In: HOLLANDA, H. B. (Org.). Pensamento feminista hoje: perspectivas decoloniais. Rio de Janeiro: Bazar do Tempo, 2020. p. 120-139.

DOW, B.; CONDIT, C. M. The State of the Art in Feminist Scholarship in Communication. Journal of Communication, v. 55, p. 448-478, 2005. 
ESCOBAR, A. Ecología Política de la globalidad y la diferencia. In: ALIMONDA, H. (Coord.). La naturaleza colonizada: Ecología política y minería en América Latina. Ediciones CICCUSCLASCO, 2011. p. 61-92.

ESCOSTEGUY, A. C. D.; MESSA, M. R. Os estudos de gênero na pesquisa em Comunicação no Brasil. In: ESCOSTEGUY, A. C. D. (Org.). Comunicação e Gênero: a aventura da pesquisa. Porto Alegre: EDIPUCRS, 2008. p. 14-29.

ESCOSTEGUY, A. C. D. Mídia e Questões de Gênero no Brasil: pesquisa, categorias e feminismos. In: XXVIII ENCONTRO ANUAL DA COMPÓS, 2019, Porto Alegre. Anais... Porto Alegre: Pontifícia Universidade Católica do Rio Grande do Sul, 2019. p. 1-21.

GONZALEZ, L. Por um feminismo afro-latino-americano. Caderno de formação politica do círculo Palmirino, n. 1. Batalha de ideias, 2011. Disponível em:https://edisciplinas. usp.br/pluginfile.php/375002/mod_resource/content/0/caderno-de-formação-do-CP_1. pdf. Acesso em: 25 mar. 2020.

GROSSI, M. P. Masculinidades: Uma revisão teórica. Revista Antropologia em Primeira Mão, v. 7, p. 21-42, 2004.

GUIMARÃES, A.; BEZERRA, C. Gestão de dados: uma abordagem bibliométrica. Perspectivas em Ciência da Informação, v. 24, n. 4, p. 171-186, 2019.

HIRATA, H. Gênero, classe e raça: interseccionalidade e consubstancialidade das relações sociais. Tempo Social, v. 26, n. 1, p. 61-73, 2014.

LOPES, D. Estudos Gays: panorâmica e proposta. In: Encontro da Associação Nacional dos Programas de Pós-Graduação em Comunicação, 10, 2001, Brasília. Anais do X Encontro da Compós. Brasília: Compós, 2001.

Desafios dos estudos gays, lésbicos e transgêneros. Comunicação, Mídia e Consumo, São Paulo, v. 1, n. 1, p. 63-73, 2004.

LUGONES, M. Colonialidade e gênero. In: HOLLANDA, H. B. (Org.). Pensamento feminista hoje: perspectivas decoloniais. Rio de Janeiro: Bazar do Tempo, 2020. p. 52-83. Colonialidad y género. In: MIÑOSO, Y. E.; CORREAL, D. G.; MUÑOZ, K. O. Tejiendo de otro modo: Feminismo, epistemología y apuestas descoloniales en Abya Yala. Popayán: Editorial Universidad del Cauca, 2014. p. 57-74.

MASSUCHIN, M. G.; TAVARES, C. Q.; SILVA, G. A. O que a produção científica tem a nos dizer? Avanços, lacunas e novas perspectivas para as pesquisas sobre Jornalismo e Gênero. Revista Paula Geral, v. 7, n. 1, p. 1-19, 2020.

MACIAS-CHAPULA, C. A. O papel da informetria e da cienciometria e sua perspectiva nacional e internacional. Ciência da Informação, v. 27, n. 2, p. 134-140, 1998.

MACHADO JUNIOR, C. et al. As leis da bibliometria em diferentes bases de dados científicos. Revista de Ciências da Administração, v. 18, n. 44, p. 111-123, 2016.

MENDES, K.; CARTER, C. Feminist and Gender Media Studies: A Critical Overview. Sociology Compass, v. 2, n. 6, p. 1701-1718, 2008.

MENDES, G. S.; FONSECA, A. B. C. A questão de gênero numa perspectiva decolonial. Revista de Educação Popular, v. 19, n. 1, p. 82-101, 2020.

MIGUEL, L. F; BIROLI, F. Feminismo e política. São Paulo: Boitempo, 2014. 
MIÑOSO, Y. E. Una crítica descolonial a la epistemología feminista crítica. El Cotidiano, n. 184, marzo-abril, 2014, p. 7-12.

MIGNOLO, W. D. Desobediência epistêmica: a opção descolonial e o significado de identidade em política. In: Cadernos de Letras da UFF - Dossiê: Literatura, Língua e Identidade, n. 34, p. 287-324, 2008.

NARIN, F.; OLIVASTRO, D.; STEVENS, K. A. Bibliometrics/Theory, practice and problems. Evaluation Review, v. 18, n. 1, p. 65-76, 1994.

OLIVEIRA, T. As políticas científicas na era do conhecimento: uma análise de conjuntura sobre o ecossistema científico global. Perspectivas da Ciência da Informação, v. 24, n. 1, p. 191-215, 2019.

OYĚWÙMÍ, O. Conceptualizing Gender: The Eurocentric Foundations of Feminist Concepts and the challenge of African Epistemologies. African Gender Scholarship: Concepts, Methodologies and Paradigms. CODESRIA Gender Series, v. 1, Dakar, 2004, p. 1-8.

SALVIATI, M. E. Manual do aplicativo Iramuteq. 2017. Disponível em: http://iramuteq. org/documentation/fichiers/manual-do-aplicativo-iramuteq-par-maria-elisabeth-salviati. Acesso em: 30 ago. 2020.

SOARES, V. Movimento feminista: Paradigmas e desafios. Revista Estudos Feministas, Florianópolis, v. 2, p. 11-24, 1994.

SARMENTO, R. Mídia, gênero e política: Breve mapeamento de horizontes analíticos. Ação Midiática, Curitiba, v. 2, n. 5, p. 1-15, 2013.

VEIGA, A. M. Gênero e cinema, uma história de teorias e desafios. Revista Estudos Feministas, Florianópolis, v. 25, n. 3, p. 1355-1357, 2017.

TOMAZETTI, T. Genealogias dissidentes: os estudos de gênero nas teses e dissertações em comunicação do Brasil (1972-2015). 2019. 201 f. Tese (Doutorado em Comunicação e Informação) - Universidade Federal do Rio Grande do Sul, Porto Alegre, 2019.

WIRTH, W.; KOLB, S. Designs and Methods of Comparative Political Communication Research. In: ESSER, F.; PFETSCH, B. (Eds.). Comparing Political Communication: Theories, Cases, and Challenges. Cambridge: Cambridge University Press, 2004. p. 87-112.

\section{Sobre as autoras}

Camilla Quesada Tavares - Professora do Programa de Pós-Graduação em Comunicação e do Curso de Comunicação Social - Jornalismo da Universidade Federal do Maranhão (UFMA/Imperatriz). Doutora em Comunicação pela Universidade Federal Fluminense (UFF). No presente artigo, a autora 
participou da concepção e desenho do estudo; aquisição, análise e interpretação dos dados; redação do manuscrito; revisão crítica do conteúdo.

Michele Goulart Massuchin - Professora do Departamento de Comunicação (DECOM), do Programa de Pós-Graduação em Comunicação (PPGCOM) e do Programa de Pós-Graduação em Ciência Política (PPGCP) da Universidade Federal do Paraná (UFPR). Doutora em Ciência Política pela Universidade Federal de São Carlos (UFSCar). No presente artigo, a autora participou do desenho do estudo; análise e interpretação dos dados; redação do manuscrito; revisão crítica do conteúdo.

Leila Lima de Sousa - Professora do curso de Comunicação Social - Jornalismo da Universidade Federal do Maranhão (UFMA/Imperatriz). Doutoranda em Ciências da Comunicação pela Universidade do Vale do Rio dos Sinos (Unisinos). No presente artigo, a autora participou da interpretação dos dados; redação do manuscrito; revisão crítica do conteúdo.

Data de submissão: 11/09/2020

Data de aceite: 25/1 1/2020 